\title{
Effect of the gastric balloon versus sham procedure on weight loss in obese subjects
}

\author{
E M RAMHAMADANY, J FOWLER, AND I M BAIRD \\ From the Department of Medicine, West Middlesex University Hospital, Isleworth, Middlexes
}

\begin{abstract}
SUMmaRY The mechanism by which intragastric balloons induce weight loss is not known, although they may act simply by reducing the amount of food needed to induce satiety. The knowledge that a balloon is present may influence the patients' eating patterns and reduce caloric intake and weight. In order to test whether the balloon or the secondary psychological effect caused weight loss, a double blind balloon versus sham procedure was devised with both groups receiving identical outpatient dietary advice (800 kcal/day). Twenty four obese women with body mass index greater than $30 \mathrm{~kg} / \mathrm{m}^{2}$ from an obesity clinic were studied. Twelve had the balloon and 12 the sham procedure. The balloon was removed after three months and the patients were followed for a further three months. There was significantly greater weight loss in the balloon group, mean weight loss (SD) of $7 \cdot 33(6 \cdot 12) \mathrm{kg}$ compared with the sham group, mean weight loss (SD) of $3 \cdot 33(3 \cdot 9) \mathrm{kg}(\mathrm{p}<0 \cdot 05)$. Weight loss was not maintained in all patients after balloon removal. Side effects were more common in the balloon group (abdominal pain, nausea, and vomiting) but resolved by the second week. We conclude that the intragastric balloon is a safe and effective method of inducing weight loss in well motivated obese patients.
\end{abstract}

Obesity is a prevalent disorder in the affluent society, and often causes serious emotional and physical disability with increased morbidity in adult life. Meaningful weight loss is frequently difficult to achieve, particularly when the goal of any reducing programme is not merely to lose weight but to maintain this loss. Many methods have been applied to reduce weight in obese subjects, dietary modification, ${ }^{1}$ increased exercise, ${ }^{2}$ appetite suppressant drugs, ${ }^{3}$ psychotherapy, ${ }^{4}$ and surgical procedures such as jaw wiring, ${ }^{5}$ jejunoileal bypass, ${ }^{6}$ or gastroplasty. Surgery for obesity is not without morbidity and mortality ${ }^{8}$ and is only acceptable after failure of other more conservative treatments. The use of intragastric devices to promote weight reduction is not new, and several researchers have used different devices over the years. De Bakey ${ }^{9}$ showed bezoars caused weight loss, Percival ${ }^{10}$ used mammary implants inflated with water and air and attached to a nasal catheter,

Address for correspondence: Dr E M Ramhamadany, Department of Medicine, West Middlesex University Hospital, Isleworth, Middlesex TW7 6AF

Accepted for publication 9 January 1989. while McFarland ${ }^{11}$ used balloons made of silicone elastomer and inflated with saline. Neiben and Harboe $^{12}$ were the first to use air tight free floating intragastric balloons (gastric ballobes) inflated with $450 \mathrm{~cm}^{3}$ air. Weight loss was achieved by almost all these devices.

The mechanism by which intragastric balloons induce weight loss in obese subjects is not clear. We investigated the effect of the gastric ballobes versus sham procedure on weight loss in obese subjects and recorded any side effects in both groups.

\section{Methods}

\section{PATIENTS}

Twenty four obese women aged 18 to 62 years, with body mass index greater than $30 \mathrm{~kg} / \mathrm{m}^{2}$ were invited to participate in the trial. All patients had failed to lose weight on conventional or very low calorie diets in the Obesity Clinic. Patients were randomised to balloon or non-balloon management according to numbers which had been previously randomly allocated, by independent observer, at the start of the 
trial and kept in a sealed envelope until the end of the study. Patients and dietitian were unaware of any individual's assigned treatment. Informed consent for gastroscopy and balloon insertion was obtained; patients were aware of the aim and the double blindness of the trial. The mean weight (SD) of the patients in the balloon group was $111.4(19 \cdot 8) \mathrm{kg}$ and the sham group was $109.6(19.4) \mathrm{kg}$, mean height was $1.63 \mathrm{~m}$ and 1.63 respectively. The mean body mass index in the balloon group was $41.9 \mathrm{~kg} / \mathrm{m}^{2}$ and in the sham group was $41 \cdot 3 \mathrm{~kg} / \mathrm{m}^{2}$.

An air tight acid resistant thermoplastic balloon (Ballobes intragastric balloon, Danish Obesity Treatment APs, Denmark) was used. The Ballobes intragastric balloon is a complete, ready packed system consisting of a balloon with one way valve attached to a tube system for the insertion and inflation of the balloon.

The gastric balloon is inserted into the stomach through the mouth and oesophagus. Once in place, the balloon is inflated with $400 \mathrm{~cm}^{3}$ room air using a modified bicycle air pump. The balloon with a one way valve is then detached and the tube system removed.

Twelve patients had the balloon inserted and inflated in the stomach with $400 \mathrm{~cm}^{3}$ air and 12 patients had the sham procedure, which involved passing the tube system down to the stomach without the balloon and pumping $400 \mathrm{cc}$ air in the stomach. All the 24 Ballobes intragastric insertion tube systems used in our study had an opaque balloon magazine at their distal ends, so neither the physician nor the patients knew if there was a balloon inside the magazine at the time of insertion. Gastroscopy was performed in all patients before the procedure to exclude oesophageal or gastric lesions and to measure the distance from the patient's incisors to the gastro-oesophageal junction. In order to avoid the influence of psychological factors on appetite and food intake, a balloon versus sham design was given to outpatients in this study. All patients received similar dietary advice of $800 \mathrm{kcal}$ daily from the dietitian who supervised the dietary habits of every patient. Neither the patient nor the dietitian knew who had the balloon. All patients had $\mathrm{H}_{2}$-receptor blockade (cimetidine $400 \mathrm{mg}$ at night) for the first three months to reduce the incidence of gastritis or gastric ulcer with the balloon.

Patients were seen every two weeks for the first three months, advised about their diets and weighed. Side effects were recorded. After three months, gastroscopy was performed to see if the balloon was still inflated and to exclude the development of gastritis or gastric ulceration. The balloon was punctured by gastroscopy using a needle for sclerosing the oesophageal varices, a rat tooth forceps then

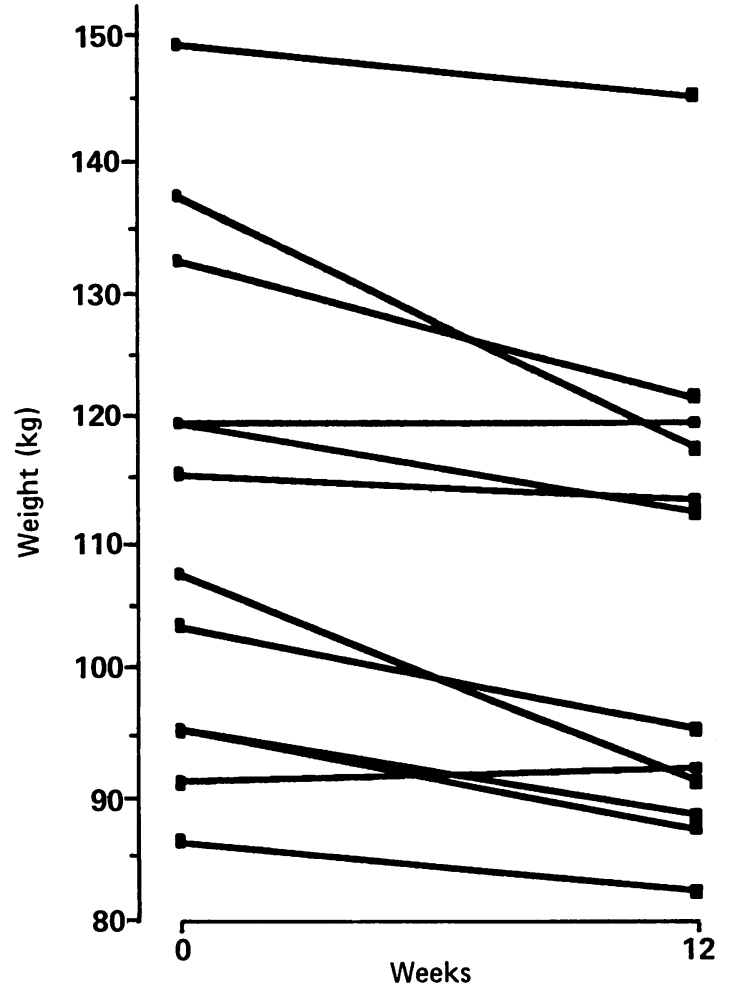

Fig. 1 Weight loss in the balloon group.

advanced through the gastroscope to grip the balloon. The air in the balloon was squeezed out by pulling gently toward the cardia. When the balloon was completely empty of air, it was removed easily with the gastroscope. Patients were followed up for a further three months after balloon removal.

\section{Results}

The balloon's insertion was a simple procedure and was successful in all patients. After three months of balloon insertion and dieting, there was significantly greater weight loss in the balloon group (Fig. 1), mean weight loss (SD) of $7 \cdot 33(6 \cdot 12) \mathrm{kg}$, compared with the sham group (Fig. 2), mean weight loss (SD) of $3.33(3.96) \mathrm{kg}(\mathrm{p}<0.05)$.

Three months after balloon removal four patients in the balloon group continued to lose weight, five patients put on weight (three of them exceeded their initial weight), two patients did not lose any further weight and one patient did not attend the follow up. The weight loss over the whole six month period of the study was still greater in the balloon group, mean weight loss (SD) of $6(9 \cdot 37) \mathrm{kg}$, compared with the sham group, mean weight loss (SD) of $3.54(4.41) \mathrm{kg}$. 


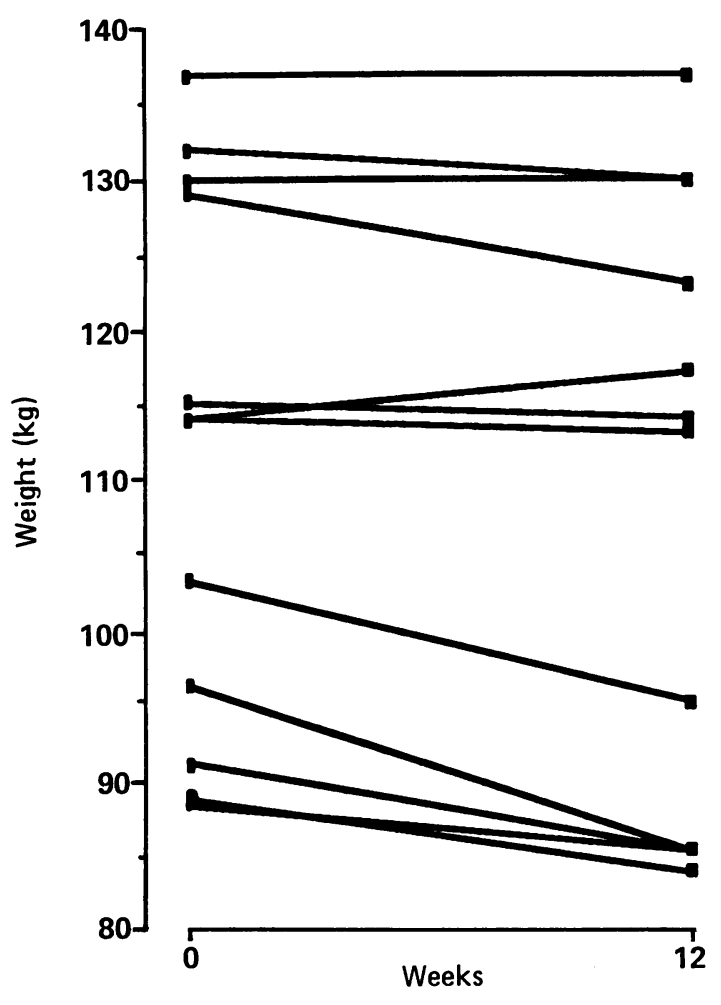

Fig. 2 Weight loss in the sham group.

Radiological examination and gastroscopy before balloon removal showed that none of the balloons had deflated spontaneously.

Side effects were more common in the balloon group than the sham group. Abdominal discomfort on sleeping on the left side (seven), abdominal cramps (eight), abdominal fullness (six), were present only in the balloon group. Vomiting (five to one), nausea (10 to four), and flatulence (six to four) were present in both groups, but more common in patients treated with the balloon. Most of the symptoms cleared by the second week, however, and no serious complications occurred.

\section{Discussion}

It has been previously shown that artificial bezoars in the stomach can cause weight loss. ${ }^{1314}$ Durans and his colleagues ${ }^{15}$ have shown that inflated balloons in the stomach of free feeding dogs reduces caloric intake. Garren showed weight loss in extremely obese patients, ${ }^{16}$ using a soft plastic cylinder bubble inflated with $200 \mathrm{ml}$ of air, but subsequent clinical trials ${ }^{1718}$ seemed to cast doubt on the efficacy of the Garren bubble. Neiben and Harboe ${ }^{19}$ in a multicentre trial on the Ballobes intragastric balloon in 202 obese patients, found it to be a safe and effective means for weight reduction (mean weight loss was $7.9 \mathrm{~kg}$ after 12 weeks treatment).

We considered it essential to have a controlled trial on the effect of the Ballobes intragastric balloon on weight loss in obese subjects. We compared a group of obese patients, who had an inflated intragastric balloon, with a group of patients who had the sham procedure. Early weight loss with the balloon was encouraging, 10 patients lost 2-20 kg in the first three months compared with nine patients in the sham group who lost $1-11 \mathrm{~kg}$ in weight. The gastric balloon was not invariably associated with weight loss, however, one patient in the balloon group did not lose any weight and another patient put on $1 \mathrm{~kg}$ in weight; both patients had strong psychosocial problems.

Weight loss with the balloon was not maintained in all the patients after balloon removal, possibly because of the poor attendance for dietary advice shown by four of the five patients who put on weight. The four patients who continued to lose weight were well motivated and attended the diet clinic regularly for weighing and advice about changing their eating habits. In our experience, patient selection is crucial for successful balloon therapy. This was shown when we studied 12 very obese subjects on the waiting list for gastroplasty: six had the Ballobes intragastric balloon and six had the sham procedure. After 12 weeks of dieting, there was no significant difference in weight loss between those patients with the balloon, mean weight loss (SD) of $2(2.97) \mathrm{kg}$, and those with the non-balloon, mean weight loss (SD) of $2.7(3.98) \mathrm{kg}$. 21 It is possible that the morbidly obese subject is an inappropriate subject for balloon therapy compared with the moderately obese.

Few serious adverse effects and complications with intragastric devices have been reported over the last few years. Intestinal obstruction ${ }^{21}$ and gastric ulceration $^{22}$ occurred in four patients treated with the Garren Bubble. Neiben and Harboe reported early transitory epigastric pain, nausea and vomiting in some of their 202 patients treated with the Ballobes intragastric balloon: gastric ulcer occurred in four patients, two patients had silent gastritis, and four patients had severe vomiting necessitating early removal of the balloon. In our study no serious adverse effects have occurred, transitory abdominal pain was present in the balloon group while nausea, vomiting, and flatulence were present in both the sham and the balloon groups but more in patients treated with the intragastric balloon. These side effects could be partly related to the procedure of balloon insertion and partly because of the presence of a foreign device (the balloon) in the stomach. Most of the symptoms, however, cleared by the second 
week. None of our patients have developed gastritis or gastric ulceration with the balloon, and none had severe or persistent vomiting necessitating early balloon removal. The zero incidence of gastritis or gastric ulcer with the Ballobes intragastric balloon in our patients might be attributable to the use of $\mathrm{H}_{2}$ receptor blockade during the balloon treatment. We reported the lack of histological changes of gastritis or campylobacter colonisation after three months balloon treatment. ${ }^{23}$

We conclude that the Ballobes intragastric balloon is a safe and effective method of weight reduction in some obese subjects. Weight loss is not maintained by all patients, however, after balloon removal. Well motivated patients who are willing to change their eating habits lose weight. We feel that a well organised dietary and behaviour modification programme are very important factors for the success of the balloon treatment. Larger volumes of air in gastric balloons have yet to be studied in man in respect of efficacy and safety. It remains to be seen whether keeping the balloon inflated for longer periods or replacing it every few months will help obese patients to achieve their target weight and maintain it.

\section{References}

1 Stunkard AJ. The pain of obesity. Palo Alto, CA: Bull Publishing Co, 1976.

2 Oscai LB, Holloszy JO. Effects of weight changes produced by exercise, food restriction or over-eating on body composition. J Clin Invest 1969; 48: 2124.

3 Sullivan AC, Comai K. Pharmacological treatment of obesity. Int J Obesity 1978; 2: 167.

4 Stuart RB, Davies B. Slim chance in a fat world: behavioural control of obesity. Champaign: Research Press Co, 1972.

5 Rodgers S, Burnet R, Goss A, et al. Jaw wiring in the treatment of obesity. Lancet 1977; i: 1221.

6 Faloon WW. Symposium on jejunoileostomy for obesity. Am J Clin Nutr 1977; 30: 1-128.

7 Buckwalter JA, Herbst CA. Gastric partition for morbid obesity: greater curvature gastroplasty or gastrogastrostomy. World J Surg 1982; 6: 403-11.

8 Bray GA, Benfield JR. Intestinal bypass for obesity. A summary and perspective. Am J Clin Nutr 1977; 30: 121.

9 De Bakey M, Ochsner A. Bezoars and concretions. A comprehensive review of the literature with an analysis of 303 collected cases and a presentation of 8 additional cases. Surgery 1938; 4: 934-63, Surgery 1939; 5: 132-60.

10 Percival WL. 'The balloon dict': non-invasive treatment for morbid obesity: preliminary report on 108 patients. Can J Surg 1984; 27: 135-6.

11 McFarland RJ, Grundy A, Pilkington TRE. The intragastric balloon: a novel idea proved ineffective. $\mathrm{Br} J$ Surg 1987; 74: 137-9.

12 Neiben OG, Harboe $H$. Intragastric balloon as an artificial bezoar for treatment of obesity. Lancet 1982; i: 198-9.

13 Davies IJ. Hairballs or haircasts of stomach and gastrointestinal tract. Lancet 1921; ii: 791-5.

14 Lal MM, Dhall JC. Trichobezoar: a collective analysis of 39 cases from India with a case report. Indian Pediatr 1975; 4: 351-3.

15 Durrans D, Taylor TV, Holt S. Volume of gastric balloon for obesity treatment determines food intake [Abstract]. Am J Gastroenterol 1987; 82: 943.

16 Garren M, Garren LR, Giordano F. The Garren gastric bubble for the morbidly obese. Endoscopic Rev 1984; 2: $57-60$.

17 Benjamin SB, Maher K, Ciarleglio C, et al. A doubleblind cross-over study of the Garren-Edwards antiobesity Bubble [Abstract]. Gastrointest Endosc 1987; 33: $168-9$.

18 Stoltenberg PH, Piziak VK, Dietscher JE. Intragastric Balloon therapy of obesity: A randomised double-blind trial [Abstract]. Gastroenterology 1987; 92: 1655.

19 Neiben OG, Harboe H. Ballobes intragastic balloon in a multicentre trial [Abstract]. Int J Obesity 1987; 11 [suppl]: 75 .

20 Ramhamadany ER, Baird IM. Effect of the gastric balloon on weight reduction in obese subjects accepted for gastroplasty [Abstract]. Int J Obesity 1988; 12: 493.

21 Benjamin SB. Small bowel obstruction and the GarrenEdwards Bubble. Lessons to be learned? [Abstract]. Gastrointest Endosc 1987; 33: 183.

22 White S. Effect of Ranitidine on the durability of Garren-Edwards Gastric Bubble [Abstract]. Gastrointest Endosc 1987; 33: 179.

23 Smith AC, Baird IM, Levi AJ, Ramhamadany ER, Owen ERTC, Price AB. Campylobacter pylori and gastritis in asymptomatic obese women before and after intragastric balloon treatment [Abstract]. Int J Obesity 1988; $12: 494$ 